\title{
CONCENTRAÇÃO DE MACRONUTRIENTES NOS RAMOS FRUTÍFEROS DO CAQUIZEIRO ${ }^{1}$
}

\author{
HIDEAKI WILSON TAKAHASHI ${ }^{2}$, RICARDO SHIGUERU OKUMURA ${ }^{3}$ \\ ALEXANDRE TAKAHASHI ${ }^{4}$
}

RESUMO-Os estudos de nutrição mineral do caquizeiro, no Brasil, de forma sistematizada, são inexistentes e bastante escassos, sendo encontrados alguns trabalhos no Japão, Nova Zelândia e Austrália. O objetivo deste trabalho foi estudar a nutrição mineral do caquizeiro cultivar Giombo, focalizando o estudo da variação da concentração de macronutrientes ao longo dos estádios de desenvolvimento nos órgãos que compõem os ramos frutíferos. O experimento foi conduzido em pomar comercial de caqui, cultivar Giombo, localizado no município de Faxina-PR. Os teores foliares de macronutrientes no estádio fenológico recomendado para avaliação do estado nutricional foram semelhantes aos da Austrália e do Japão e continham 20,30; 1,25; 30,55; 23,45; 3,85 e 3,05 $\mathrm{g} \mathrm{kg}^{-1}$ de massa seca de $\mathrm{N}, \mathrm{P}, \mathrm{K}, \mathrm{Ca}, \mathrm{Mg}$ e $\mathrm{S}$, respectivamente.

Termos para Indexação: Concentração de macronutriente, caqui, estádio vegetativo.

\section{NUTRIENT CONCENTRATION IN REPRODUCTIVE BRANCHES OF PERSIMMON}

\begin{abstract}
The studies on mineral nutrition of persimmon in Brazil, at a systematic form, are inexistent and quite scarce, but some studies can be found in Japan, New Zealand and Australia. This work had the objective to study the mineral nutrition of persimmon, cv. Giombo, focusing on the variation of macronutrients concentration during the development stages of the organs that compose the reproductive branches. The experiment was conducted in a commercial orchard of persimmon, cv. Giombo, located in Faxina, state of Paraná, Brazil. Foliar levels of macronutrients, in the recommended phenological stage to evaluate the nutritional status, were similar to Australia and Japan and contained 20.30, 1.25, 30.55, 23.45, 3.05 and $3.85 \mathrm{~g} \mathrm{~kg}^{-1}$ of dry weight for $\mathrm{N}, \mathrm{P}, \mathrm{K}, \mathrm{Ca}, \mathrm{Mg}$ and $\mathrm{S}$, respectively.
\end{abstract}

Index terms: nutrients concentration, persimmon, vegetative stage.

\section{INTRODUÇÃO}

Os estudos de nutrição mineral do caquizeiro, no Brasil, de forma sistematizada, como em outras culturas de maior importância econômica, são escassos e, entre eles, são frequentes os trabalhos do Japão, Nova Zelândia e Austrália, que forneceram dados preliminares importantes para o presente trabalho.

A determinação do teor de nutriente nos tecidos das folhas estrategicamente escolhidas em épocas adequadas serve para avaliar o estado nutricional das plantas. O método da análise foliar é a mais importante estratégia para diagnose de deficiências e excessos nutricionais, e o estabelecimento de recomendação de adubação para árvores frutíferas, devendo levar em consideração, na interpretação, vários fatores, tais como idade e posição da folha, estado de frutificação e estádio fenológico (SMITH, 1986).
A absorção dos nutrientes é diferente de acordo com a fase de desenvolvimento da cultura e do elemento, normalmente na maioria das espécies frutíferas, intensificando-se a partir do início da formação dos frutos. Por isso, além da quantidade absorvida de nutrientes, deve ser considerada também sua concentração nos diferentes estádios de desenvolvimento (MALAVOLTA et al., 1997; VITTI et al., 1994), servindo assim para monitorar a transferência de nutrientes entre os órgãos, nos diferentes estádios, bem como a época de maior necessidade de se ter esses elementos disponíveis no solo para a planta.

Existem métodos científicos para estabelecer a melhor posição e idade da folha para representar o estado nutricional de uma cultura perene e anual. Esses métodos baseiam-se no princípio de que os tecidos são sensíveis à mudança de disponibilidade de nutrientes pelo solo, e essa sensibilidade ocorre em um determinado período do ano.

\footnotetext{
1(Trabalho 110-09). Recebido em: 04-05-2009. Aceito para publicação em: 04-11-2010. (autor para correspondência).

${ }^{3}$ Eng $^{\circ}$ Agr ${ }^{\circ}$. Mestrando em Agronomia, Universidade Estadual de Londrina-PR. Bolsista da CAPES.

${ }^{4}$ Acadêmico do Curso de Agronomia, Universidade Estadual de Londrina-PR.
}

${ }^{2} \mathrm{Eng}^{\circ} \mathrm{Agr}^{\circ}$. Prof. Associado. Depto. Agronomia. UEL - PR. C.P. 6001. CEP 86051-990 Londrina - PR. E-mail: hwilson@uel.br 
O tecido normalmente utilizado para avaliar o estado nutricional do caquizeiro é a folha recémmadura de ramos não frutíferos, amostrado aproximadamente dois meses antes da colheita (AOBA; KONNO, 1984). Entretanto, Clark e Smith (1990a) verificaram que não houve diferenças estatísticas entre a concentração de nutrientes em folhas amostradas de ramos frutíferos e não frutíferos. Segundo Nakamura et al. (1972a, b) e Sato et al. (1954), a interpretação da análise é feita pela comparação das concentrações ótimas estabelecidas, através de observações em pomares comerciais de altas produtividades, em áreas de produção significativa.

Sato et al. (1954), estudando no Japão, obtiveram valores de $\mathrm{N}(22,2-32,5), \mathrm{P}(1,1-1,6), \mathrm{K}$ (14,7-386), Ca (9,2-27,8) e $\mathrm{Mg}(2,2-7,7) \mathrm{em} \mathrm{g} \mathrm{kg}^{-1} \mathrm{de}$ matéria seca. Resultados similares foram observados na Nova Zelândia, por Clark e Smith (1990a), que encontraram teores de $\mathrm{N}(14,5-26,1), \mathrm{P}(0,9-1,6), \mathrm{K}$ $(21,5-39,6), \mathrm{Ca}(13,0-33.9)$ e $\mathrm{Mg}(2,5-5,2) \mathrm{em} \mathrm{g} \mathrm{kg}^{-1}$ de matéria seca.

O objetivo deste trabalho foi estudar a nutrição mineral do caquizeiro cultivar Giombo, focalizando o estudo da variação da concentração de macronutrientes ao longo dos estádios de desenvolvimento nos órgãos que compõem os ramos frutíferos e sugerir valores de concentrações iniciais para a interpretação do estado nutricional do caquizeiro cultivado em condições semelhantes à deste experimento.

\section{MATERIAL E MÉTODOS}

O experimento foi conduzido em pomar comercial de caqui, cultivar Giombo, com 12 anos de idade, localizado no município de Faxinal, região norte do Paraná (coordenadas geográficas $23^{\circ} 58^{\prime} \mathrm{S}$ e $51^{\circ} 19^{\prime} \mathrm{W}$ ) e a altitude média de $910 \mathrm{~m}$. O clima é do tipo subtropical $\mathrm{Cfb}$ (segundo classificação de Köeppen). O solo é classificado como Latossolo Vermelho distroférrico (EMBRAPA, 1999). O resultado da análise química do solo antes da implantação do experimento está apresentado na Tabela 1 .

$\mathrm{O}$ delineamento estatístico foi o de blocos casualizados, com 5 repetições, sendo cada planta uma parcela.

A área experimental era composta de 75 plantas de caqui, com espaçamento de $7.0 \times 6.0 \mathrm{~m}$ e os tratamentos constituídos pelas 15 épocas de coleta do material, e em cada época amostraram-se aleatoriamente 10 ramos frutíferos $/$ planta $^{-1}$, com intervalo de coleta de 3 semanas, iniciando com 3 semanas após a brotação e prosseguindo até 45 semanas após a brotação. Cada planta continha em média 235 ramos produtivos, com comprimento de $24 \mathrm{~cm}$, e estes apresentaram 11,4 folhas e 3,4 frutos com comprimento de $24 \mathrm{~cm}$.

Para análise química, primeiramente, eles foram separados em folhas, frutos e ramos, lavados em água corrente e enxaguados em água destilada para posterior secagem até peso constante. Depois, foi efetuada a moagem em moinho tipo Willey e armazenado em saquinhos de polipropileno até o momento da digestão. A análise química foi realizada segundo metodologia descrita por Malavolta et al. (1989). Foram aplicados durante o experimento 40 $\mathrm{kg}$ de $\mathrm{N}$ por ha na forma de sulfato de amônio.

\section{RESULTADOS E DISCUSSÃO}

A concentração foliar inicial dos macronutrientes aniônicos N, P e S (Figuras 1; 2 e 6) apresentou teores elevados em relação aos macronutrientes catiônicos K, Ca e Mg (Figuras 3; 4 e 5), no período de três semanas após a brotação, mostrando que os macronutrientes aniônicos foram transferidos rapidamente dos locais de reserva para as folhas logo no início do desenvolvimento e que a seiva circulante que atingia esse órgão já continha altas concentrações. Inferiu-se o, assim, que os macronutrientes aniônicos não tiveram dificuldade em ser transferidos para as folhas nesse estádio de desenvolvimento. Portanto, deve-se levar em consideração que a maioria dos espaços existentes no vegetal, principalmente em troncos e ramos do ano anterior, possui acentuada carga negativa, e isso dificulta a movimentação de cátions e facilita a de ânions, principalmente nessa fase inicial com reduzida área foliar (CROOKE; KNIGHT, 1962).

Ao longo do ciclo vegetativo, as concentrações desses nutrientes diminuem, devido ao efeito da diluição ocorrida pelas folhas em crescimento e redistribuição de nutrientes para outros órgãos da planta, até o final do ciclo (NACHTIGALL; DECHEN, 2006). Como parte do conteúdo de ramos novos é consequência da transferência de reserva contida nos ramos do ano anterior, no início, a concentração é alta, e à medida que a fotossíntese se manifesta, vai ocorrendo diluição. Comparando as concentrações foliares de P (Figura 2) com as de N (Figura 1) e K (Figura 3 ), verifica-se que são inferiores em qualquer fase do ciclo da planta. Essa tendência foi observada por Nachtigall e Dechen (2006), no Brasil, para a cultura da maçã.

Os cátions $\mathrm{Ca}$ e $\mathrm{Mg}$ foliar apresentaram concentração baixa nas três semanas do início da brotação, consequências de possuir pequena super- 
fície transpiratória e baixa mobilidade interna por caminhar principalmente pelo xilema. Analisando a concentração inicial dos macronutrientes, o N (Figura 1) apresentou a maior concentração, seguido do $S$ (Figura 6), e em menor concentração o Mg (Figura 5), sendo seus valores próximos de 34; 20 e $3 \mathrm{~g} \mathrm{~kg}^{-1}$ de massa seca de folha, respectivamente.

Os cátions $\mathrm{Ca}$ (Figura 4) e Mg (Figura 5) foliar aumentaram significativamente suas concentrações ao longo dos estádios de desenvolvimento. Já com relação à concentração de $\mathrm{K}$, essa tendência foi até as 12 semanas após o início da brotação, sendo que, em seguida, houve um declínio contínuo até o final do ciclo, mostrando que ocorreu grande transferência desse elemento da folha para o fruto. Essa tendência foi relatada para espécies frutíferas de clima temperado como caqui (GEORGE et al., 1995), maçã e pêssego (ROBINSON, 1986), pecã (SPARKS, 1977) e cítrus (JONES; EMBLETON, 1968).

Avaliando individualmente as concentrações desses macronutrientes ao longo do ciclo, o Ca foliar (Figura 4) foi o elemento que mais acumulou nesse órgão, partindo de uma concentração inicial de $4 \mathrm{~g} \mathrm{~kg}^{-1}$ e atingindo, com 36 semanas de idade, valor superior a $35 \mathrm{~g} \mathrm{~kg}^{-1}$, resultado semelhante encontrado por Nachtigall e Dechen (2006) e Leece e Gilmour (1974), respectivamente, em maçã e caqui. Tal observação serve para confirmar que o cálcio é um nutriente de difícil redistribuição na planta, acumulando-se nas folhas, que é o final da via xilemática (LARCHER, 2000). Outro fator que pode agravar essa situação é a competição entre $\mathrm{K} \mathrm{e} \mathrm{Ca}$, que acontece dentro da planta (MALAVOLTA et al. 1997), já que o maior fluxo de potássio para o fruto de caqui concorre para diminuir a presença de cálcio.

A maior parte do $\mathrm{Ca}$ do fruto (Figura 4) acumulou-se nos estádios iniciais do desenvolvimento. Essa tendência foi verificada em kiwi (CLARK; SMITH, 1988) e maçã (VAN GOOR; VAN LUNE, 1980), podendo observar que os valores da concentração de $\mathrm{Ca}$ nos frutos na maturação fisiológica, entre 30 e 33 semanas após a brotação, reduziram-se praticamente a traços de $\mathrm{Ca}$. Resultado semelhante foi verificado em maçã por Nachtigall e Dechen (2006), no período compreendido de 20 a 25 semanas após o florescimento pleno. Em muitas culturas, esse baixo nível de Ca no fruto tem trazido problemas durante o armazenamento pela má-formação do tecido, como no caso da maçã (SHARPLESS; JOHNSON, 1977). No caqui, ainda não se têm estudos relacionados com Ca e qualidade de fruto, porém algumas observações de campo têm apontando o amolecimento de frutos durante o processo de destanização causado pela deficiência de Ca nesse órgão.
$\mathrm{O} \mathrm{Mg}$ (Figura 5), que é tido como elemento com mobilidade mediana, teve a mesma tendência do Ca nos três órgãos estudados, apresentando maior acúmulo nas folhas; muito provavelmente, por fazer parte da molécula de clorofila, pois de acordo com Marschner (1995), dependendo do estado nutricional de Mg na planta, de 6 a 25\% do magnésio total podem estar ligados à molécula de clorofila, enquanto outros 5 a $10 \%$ ligados a pectatos na parede celular ou depositados como sal solúvel no vacúolo. O máximo de concentração nas folhas alcançado no final do ciclo foi de 5-6g de $\mathrm{Mg} \mathrm{kg}^{-1}$ de massa seca, valor 5 a 6 vezes menor do que o Ca; observando também concentração muito baixa de $\mathrm{Mg}$ nos frutos.

A concentração de K nos frutos (Figura 3), nos estádios compreendidos entre 6 e 21 semanas após a brotação, teve queda vertiginosa apesar de a massa seca de fruto ter permanecido sem alteração nesse período. Já no período de 30 a 36 semanas após a brotação, a massa seca de fruto teve aumento vertiginoso, no entanto a concentração de $\mathrm{K}$ permaneceu entre $8-10 \mathrm{~g}_{\text {de }} \mathrm{K} \mathrm{kg}^{-1}$ de massa seca de fruto, ocorrendo um leve aumento no final da maturação, mostrando que houve intensa absorção desse elemento pela planta e indicando a necessidade da presença desse nutriente no solo. A concentração superior a $8 \mathrm{~g}$ de $\mathrm{K} \mathrm{kg}^{-1}$ de massa seca de fruto, em contraste

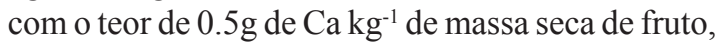
evidencia outra dificuldade do transporte de Ca para o fruto, pois esses dois cátions são antagônicos, tanto no processo de absorção quanto no de transporte.

O teor de N (Figura 1) nos órgãos estudados ao longo dos estádios fenológicos da cultura comportou-se diferentemente. O teor foliar e do caule no início do ciclo foi alto, sendo que o primeiro teve um decréscimo lento, apresentando o mínimo teor de $10 \mathrm{~g}_{\text {de }} \mathrm{N} \mathrm{kg}^{-1}$ de matéria seca, com 36 semanas após a brotação, enquanto o teor de $\mathrm{N}$ do caule teve uma queda acentuada até 18 semanas após a brotação, mantendo baixa e constante até 33 semanas após a brotação. Após esse período, houve uma tendência de aumento do teor de $\mathrm{N}$ no caule

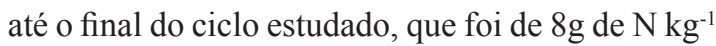
de matéria seca de caule (Figura 1). Este resultado mostra uma transferência de $\mathrm{N}$, de outros órgãos para o caule. Esta locomoção do ponto de vista do próximo ciclo é muito benéfica, pois funciona como reserva para sustentar a fase inicial da nova brotação. Alguns trabalhos estão sendo realizados com o intuito de reforçar esta transferência de N, para isto, alguns técnicos japoneses vindos ao Brasil através da Japan International Cooperation Agency (JICA), estão recomendando reforço de cobertura de $\mathrm{N}$ na fase final de maturação do fruto para ser transferido 
ao ramo que sustentará a próxima safra.

Verifica-se que a massa seca de folhas e caule, depois de 9 semanas após a brotação, permaneceu constante e num percentual muito pequena em relação à massa seca de frutos, enquanto a acumulação de massa seca dos frutos após 12 semanas continuou crescendo vertiginosamente até após o início do ponto de colheita, que ficou compreendido entre 30 e 33 semanas após o início da brotação (Figura 7). Clark e Smith (1990b), na Nova Zelândia, com caqui "Fuyu", observaram dois períodos de intenso crescimento, 10-12 semanas após a polinização, e de 18 semanas após a polinização até a colheita, separado por um período de menor crescimento, que foi de 6-7 semanas. Resultado semelhante foi observado por Nachtigall e Dechen (2006) em maçã, onde a massa seca acumulada foi pequena até a $7^{\mathrm{a}}$ semana após o florescimento pleno; a partir desse período, houve aumento expressivo da massa seca acumulada até o final do ciclo. Essa tendência mostra que os fotossintetatos foram produzidos intensamente pelas folhas, transportados via caule e acumulados em grande quantidade nos frutos. Do ponto de vista da produtividade, o máximo acúmulo de massa seca de frutos nessas condições experimentais ocorreu no início da senescência e queda das folhas apesar de que a maioria dos produtores inicia a colheita no período mencionado anteriormente para ter maior período de comercialização.

$\mathrm{Na}$ Tabela 2, encontram-se os resultados de teores médios de macronutrientes nas folhas de caqui amostrados em diferentes países, com condições climáticas completamente diferentes e com manejo de solo provavelmente distinta, além da cultivar, idade do pomar,etc. Mesmo assim, os valores neste estádio de desenvolvimento apresentaram-se muito próximos um do outro, com as maiores diferenças para os teores de $\mathrm{Mg}$ e $\mathrm{S}$, sendo que os teores encontrados neste estudo foram relativamente menores do que os da literatura. Portanto, até que surjam dados mais regionais e particularizados para cada região de produção, os dados constantes na Tabela 2 podem ser utilizados para a avaliação do estado nutricional de pomares de caqui no Brasil.

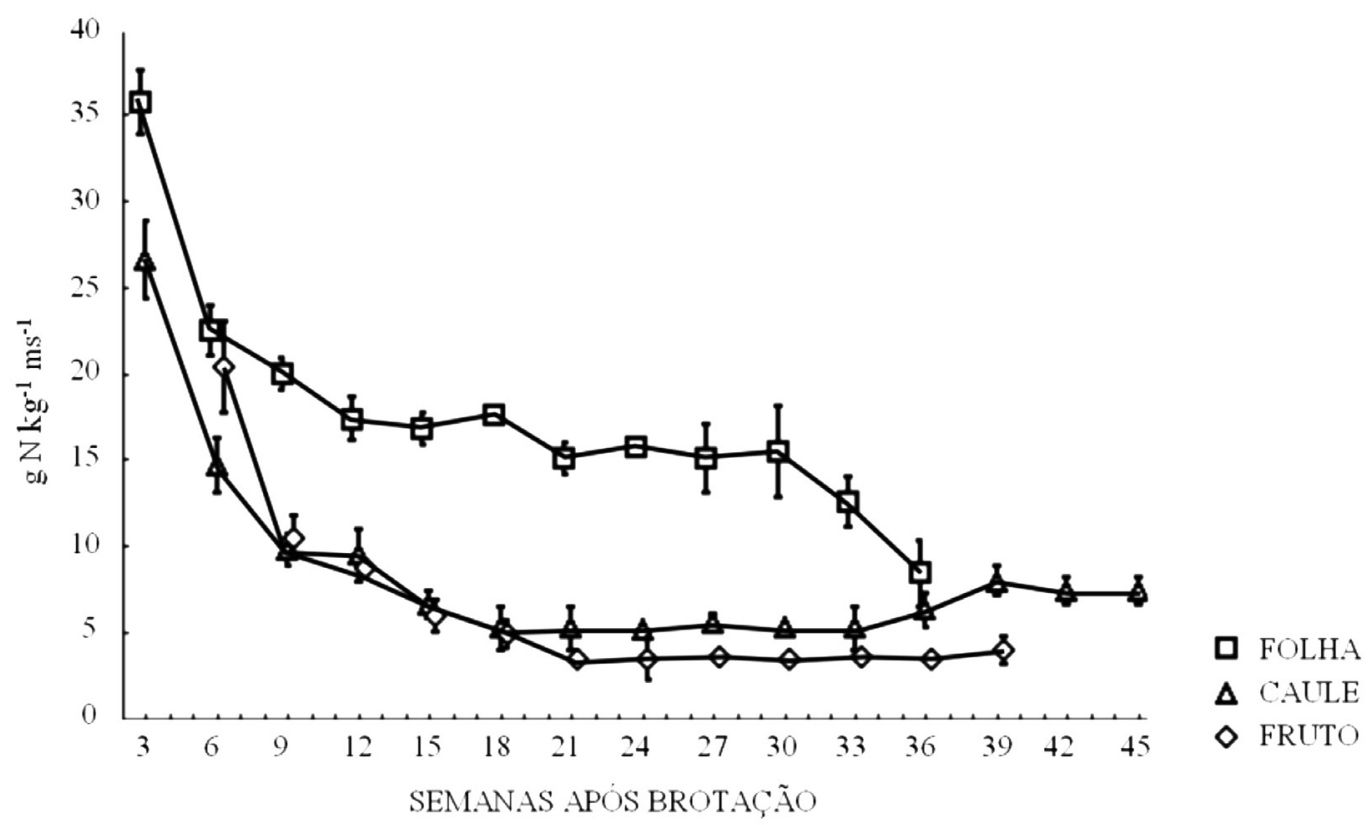

FIGURA 1 - Concentração de Nitrogênio nas folhas, frutos e caules de ramos frutíferos de caquizeiro cultivar Giombo, ao longo do estádio de desenvolvimento. 


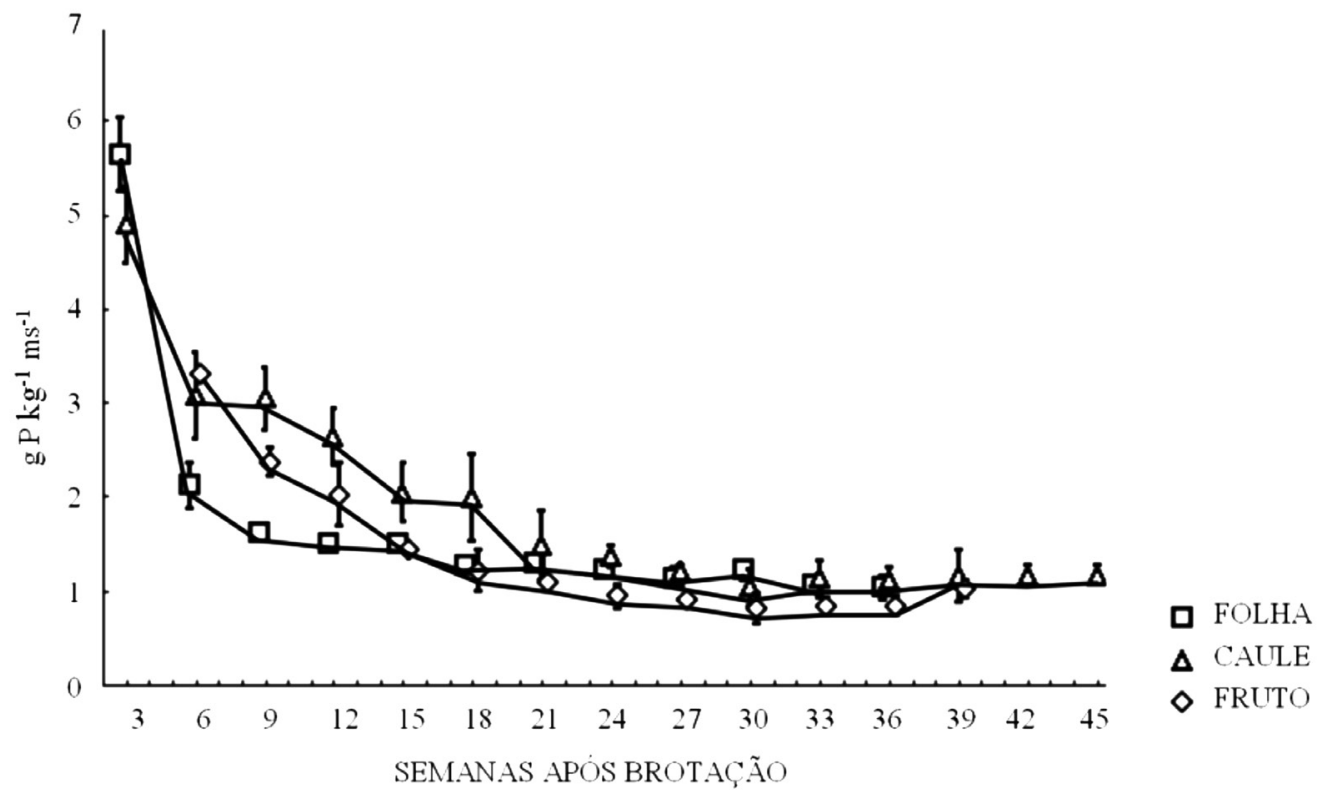

FIGURA 2 - Concentração de Fósforo nas folhas, frutos e caules de ramos frutíferos de caquizeiro cultivar Giombo, ao longo do estádio de desenvolvimento.

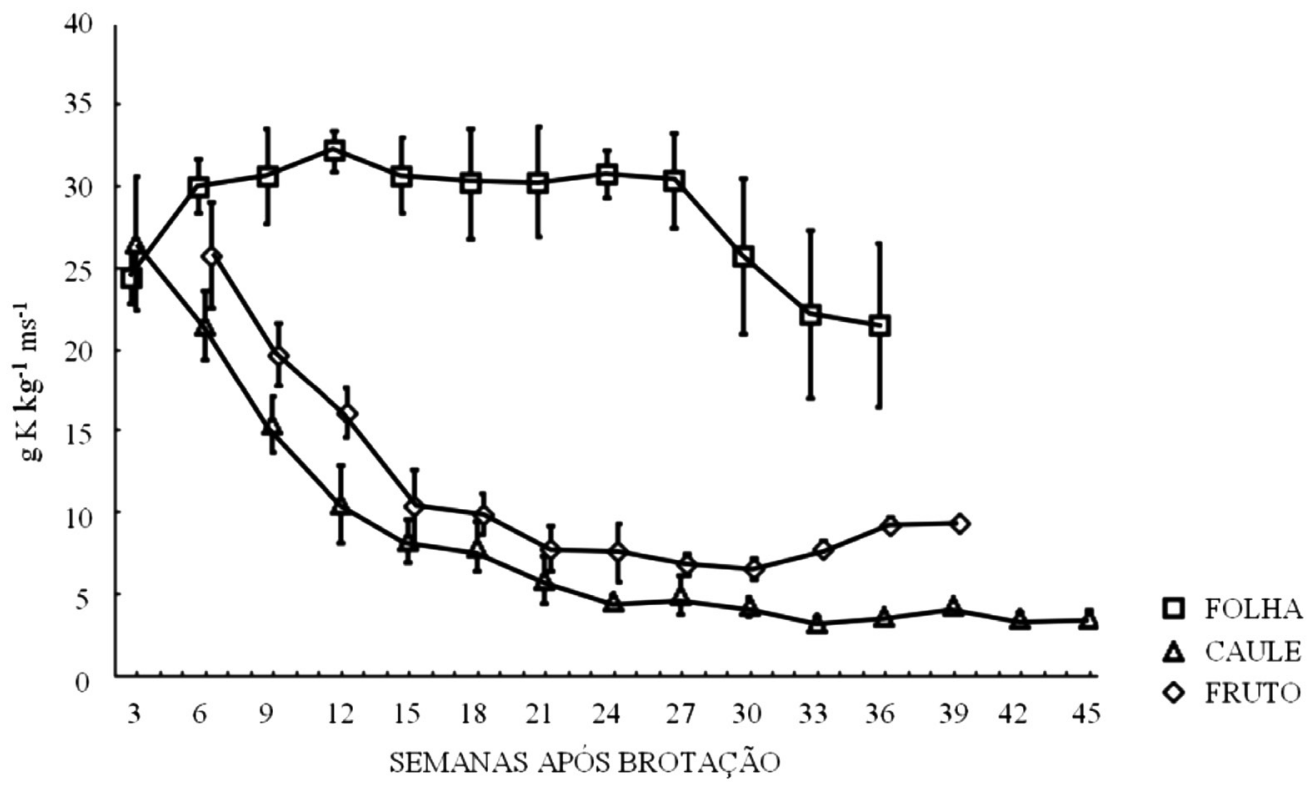

FIGURA 3- Concentração de Potássio nas folhas, frutos e caules de ramos frutíferos de caquizeiro cultivar Giombo ao longo do estádio de desenvolvimento. 


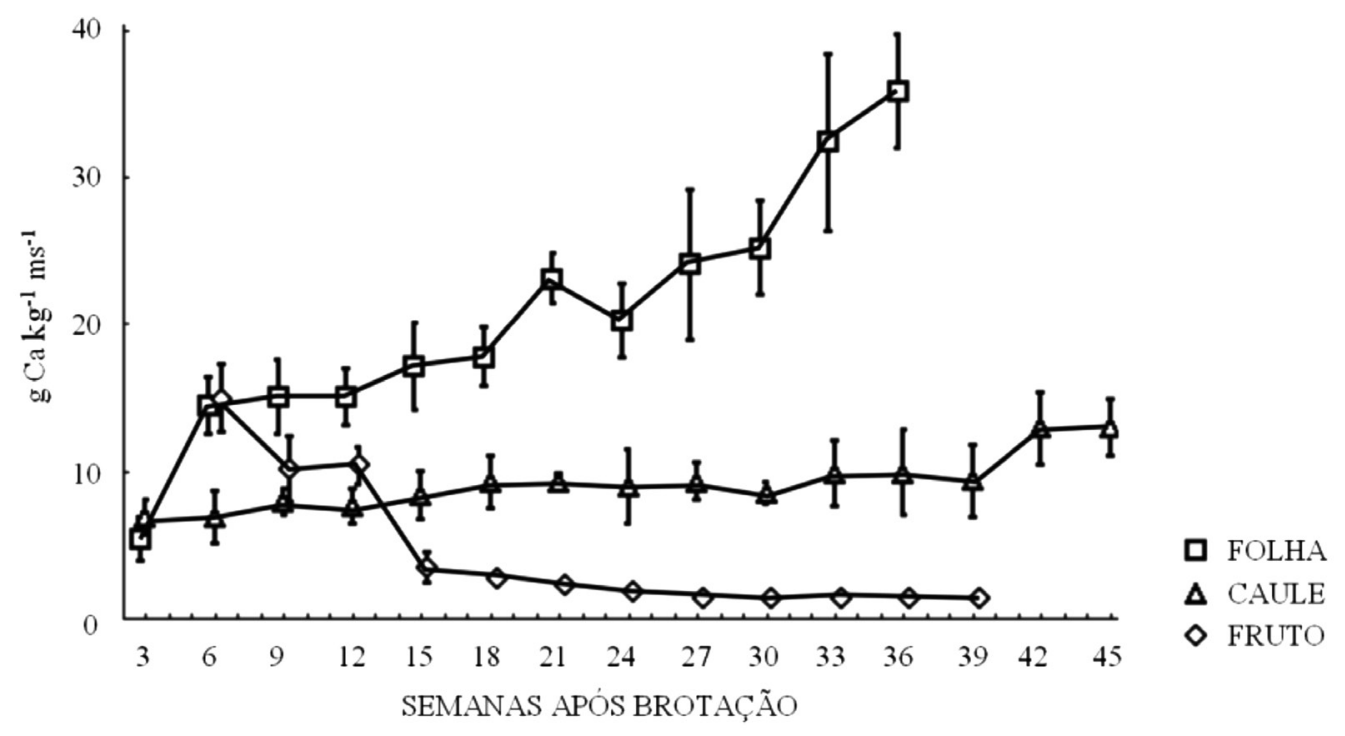

FIGURA 4 - Concentração de Cálcio nas folhas, frutos e caules de ramos frutíferos de caquizeiro cultivar Giombo, ao longo do estádio de desenvolvimento.

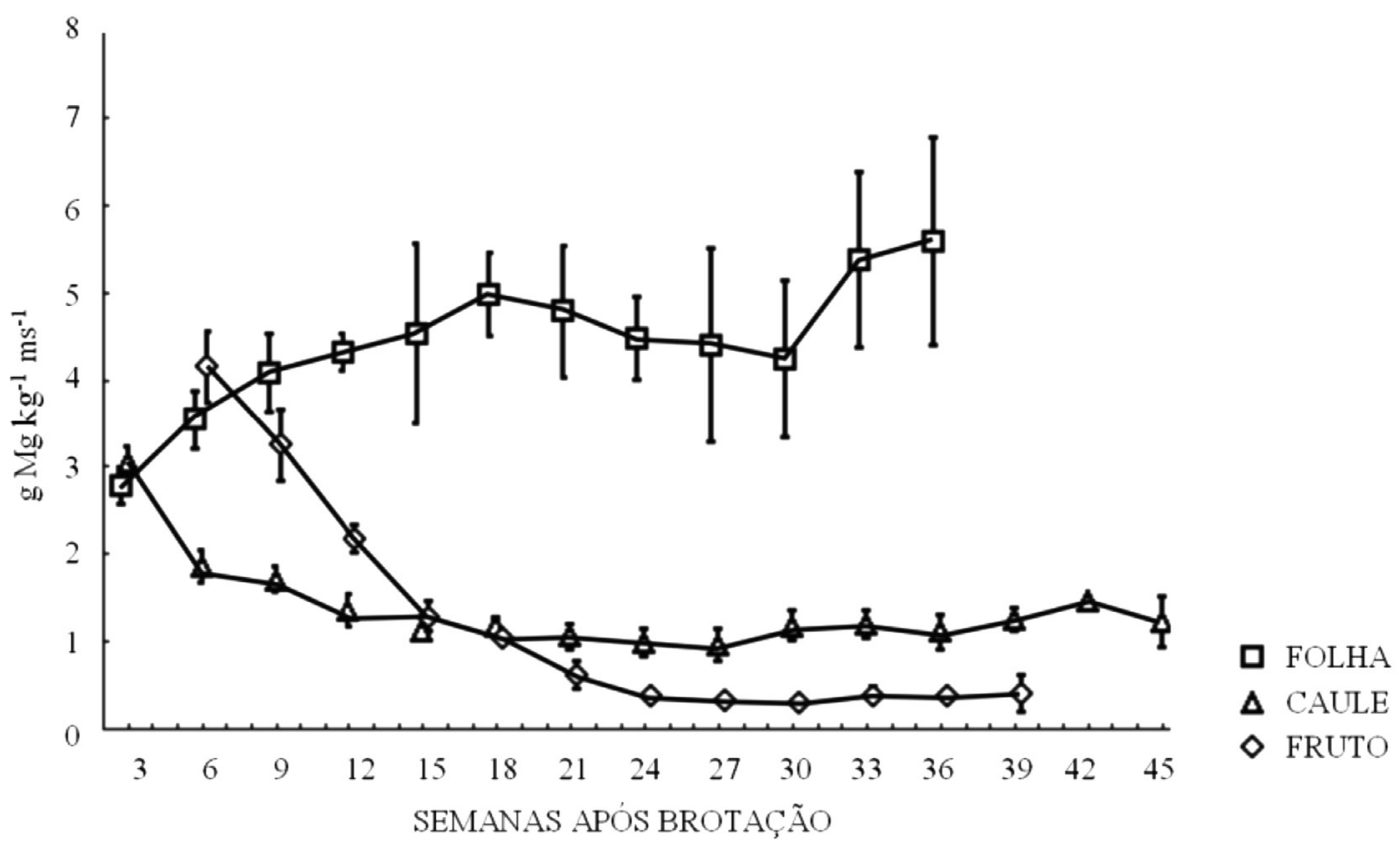

FIGURA 5 - Concentração de Magnésio nas folhas, frutos e caules de ramos frutíferos de caquizeiro cultivar Giombo, ao longo do estádio de desenvolvimento. 


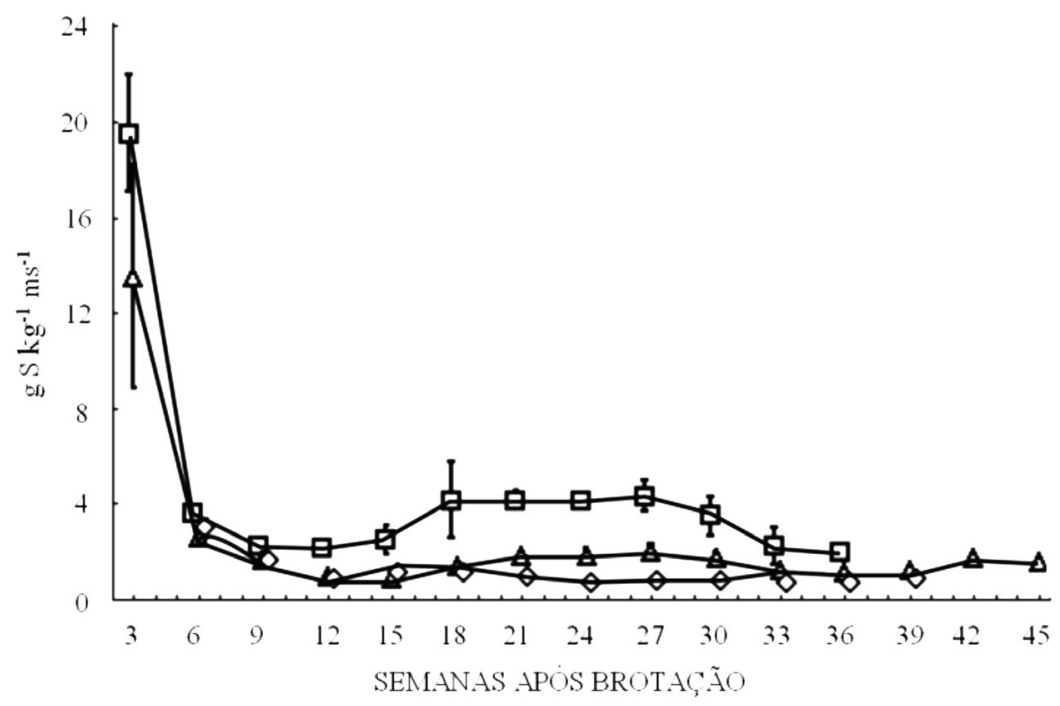

口 FOLHA

$\Delta$ CAULE

$\diamond$ FRUTO

FIGURA 6 - Concentração de Enxofre nas folhas, frutos e caules de ramos frutíferos de caquizeiro cultivar Giombo, ao longo do estádio de desenvolvimento.

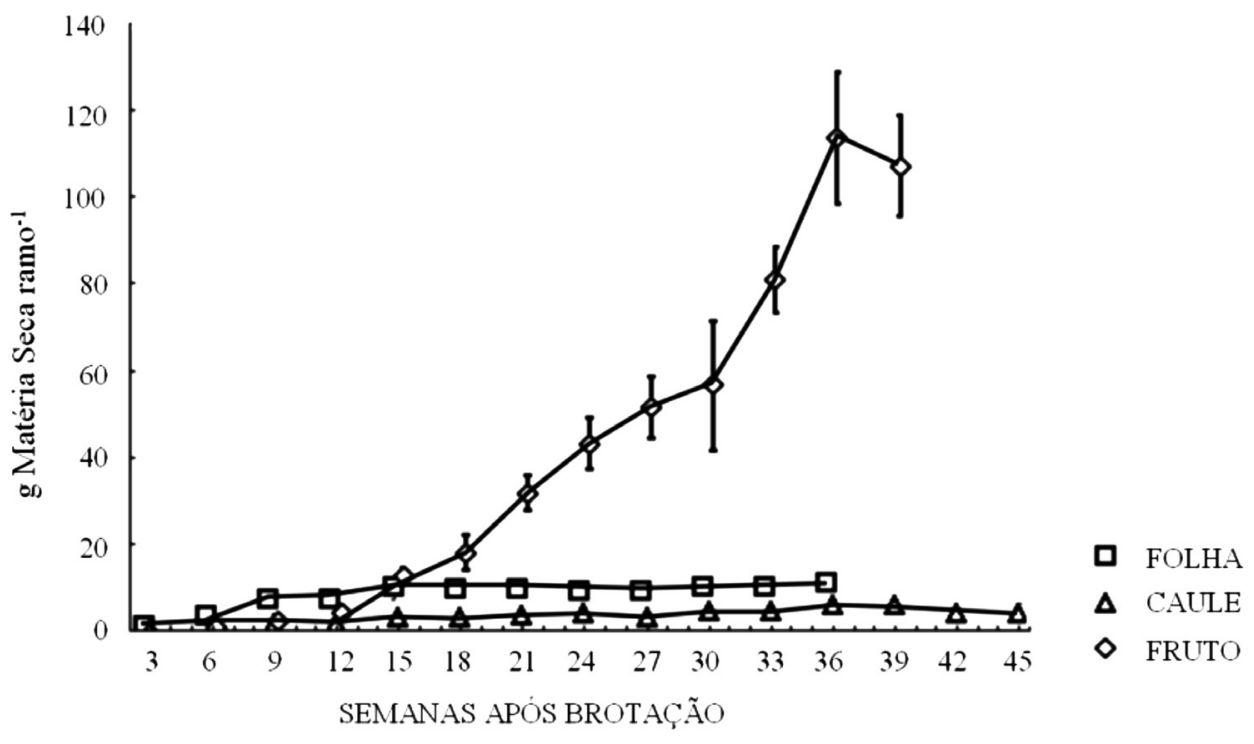

FIGURA 7- Peso da matéria seca nas folhas, frutos e caules de ramos frutíferos de caquizeiro cultivar Giombo, ao longo do estádio de desenvolvimento. 
TABELA 1 - Resultado da análise química do solo antes da implantação do experimento, constituinte da camada arável $0-20 \mathrm{~cm}$, município de Faxina-PR.

\begin{tabular}{|c|c|c|c|c|c|c|c|c|c|c|c|}
\hline Bloco & $\mathbf{p H}^{*}$ & $\mathbf{C a}^{+2}$ & $\mathrm{Mg}^{+2}$ & $\mathbf{A l}^{+3}$ & $\mathbf{H}+\mathbf{A l}$ & $\mathbf{K}^{+}$ & CTC & $\mathbf{C}$ & M.O. & V & $\mathbf{P}^{* *}$ \\
\hline \multicolumn{8}{|c|}{----- $\mathrm{cmol}_{\mathrm{c}} \mathrm{dm}^{-3}$----- } & \multicolumn{2}{|c|}{--- $\mathrm{g} \mathrm{kg}^{-1}$--- } & $\%$ & $\mathrm{mg} \mathrm{dm}^{-3}$ \\
\hline 1 & 4,60 & 3,30 & 1,00 & 0,25 & 6,69 & 0,18 & 11,17 & 14,5 & 25,7 & 40,1 & 9,30 \\
\hline 2 & 4,80 & 3,30 & 1,60 & 0,15 & 5,76 & 0,20 & 10,86 & 9,7 & 16,7 & 47,0 & 17,10 \\
\hline 3 & 4,90 & 2,60 & 1,10 & 0,10 & 4,96 & 0,20 & 8,86 & 9,0 & 15,4 & 44,0 & 22,80 \\
\hline 4 & 5,88 & 2,58 & 1,02 & 0 & 3,63 & 0,26 & 7,49 & ----- & ---- & 51,5 & 32,92 \\
\hline 5 & 5,88 & 2,58 & 1,02 & 0 & 3,63 & 0,26 & 7,49 & ----- & ----- & 51,5 & 32,92 \\
\hline
\end{tabular}

TABELA 2 - Teores foliares médios de macronutrientes no caqui, em diferentes países, amostrados entre a $21^{\mathrm{a}}$ e $23^{\mathrm{a}}$ semana após a brotação.

\begin{tabular}{ccccccc}
\hline & $\mathbf{N}$ & $\mathbf{P}$ & $\mathbf{K}$ & $\mathbf{C a}$ & $\mathbf{M g}$ & $\mathbf{S}$ \\
\cline { 2 - 7 } & -------------- & $\mathrm{g} \mathrm{kg}$ & Matéria Seca & ------------- \\
Clark e Smith (1990a)-Austrália & 15,40 & 1,26 & 30,41 & 21,64 & 4,62 & 4,15 \\
Sato et al. (1954)-Japão & 26,90 & 1,35 & 26,70 & 18,50 & 4,95 & ---- \\
Faxinal-PR-Brasil & 20,30 & 1,25 & 30,55 & 23,45 & 3,85 & 3,05 \\
\hline
\end{tabular}

\section{CONCLUSÕES}

1-As concentrações foliares iniciais de macronutrientes aniônicos são maiores do que os catiônicos.

2-Os teores foliares de $\mathrm{Ca}$ e $\mathrm{Mg}$ aumentam com o passar dos ciclos fenológicos e o K segue essa tendência até a $12^{\mathrm{a}}$ semana após o início da brotação.

3-O teor de Ca nos frutos declina com o crescimento do mesmo e atinge teores ínfimos, 0,5 g de Ca por $\mathrm{kg}$ de massa seca de fruto, no período de colheita.

4-O K no fruto, apesar do crescimento acentuado da massa seca do fruto no final do ciclo, mantem teor superior a $8 \mathrm{~g}$ de $\mathrm{K}$ por $\mathrm{kg}$ de massa seca de fruto.

5-A massa seca de folhas e caule após a nona semana de brotação permanece constante até o final do ciclo, enquanto a massa do fruto cresce até o ponto de maturação fisiológica.

6-Os teores foliares de macronutrientes na folha-índice são semelhantes aos da Austrália e do Japão.

\section{REFERÊNCIAS}

AOBA, K.; KONNO, S. Studies on the minor metal elements in orchards. X. The relationship between greenish spot disorder of Japanese persimmon fruit and excess manganese absorption. Bulletin Fruit Tree Research Station Serie A, Hiroshima, n.11, p. 55-68, 1984.

CLARK, C.J.; SMITH, G.S. Seazonal accumulation of mineral nutrients by kiwifruit. New Phytologist, Cambridge, v. 108, p. 399-409, 1988.

CLARK, C.J.; SMITH, G.S. Seasonal changes in the composition, distribution and accumulatioin of mineral nutrients in persimmon fruit. Scientia Horticulturae, Amsterdam, n.42, p. 99-111, 1990b.

CLARK, C.J.; SMITH, G.S. Seasonal changes in the mineral nutrient content of persimmon leaves. Scientia Horticulturae, Amsterdam, n.42, p. 85 97, 1990a.

CROOKE, W.M.; KNIGHT, A.H. An evaluation of published data on the mineral composition of plants in the light of cátion exchange capacities of their roots. Soil Science, Baltimore, n.93, p. 365-373, 1962.

EMBRAPA. Sistema brasileiro de classificação de solos. Brasília: Embrapa, 1999. 412p. 
GEORGE, A.P.; NISSEN, R.J.; COLLINS, R.J.; HAYDON, G.F. Seasonal leaf nutrient patterns and standard leaf nutrient levels for non-astringent persimmon in subtropical Australia. Journal of Horticultural Science, Budapest, v.5, n.70, p. 807$816,1995$.

GOOR van, B.J.; LUNE van, P. Redistribution of potassium, boron, iron, magnesium and calcium in apple trees determined by an indirect method. Physiologia Plantarum, Copenhagem, v. 48, p. 21-26, 1980.

JONES, W.W.; EMBLETON, T.W. The influence of the amount of fruit and time of harvest on macronutrient concentrations in 'Valencia' orange leaves. Proceedings of the American Society for Horticultural Science, Alexandria, n.92, p. 191-194, 1968.

LEECE, D.R.; GILMOUR, A.R. Diagnostic leaf analysis for stone fruit. 2. Seasonal changes in the leaf composition of peach. Australian Journal of Experimental Agriculture Animal Husbandry, Melbourne, n.14, p. 822-827, 1974.

MALAVOLTA, E.; VITTI, G.C.; OLIVEIRA, S.A. Avaliação do estado nutricional de plantas: princípios e aplicações. Piracicaba: Potafós, 1989. 201p.

MALAVOLTA, E.; VITTI, G.C.; OLIVEIRA, S.A. Avaliação do estado nutricional das plantas: princípios e aplicações. 2. ed. Piracicaba: Potafós, 1997. 319p.

MARSCHNER, H. Mineral nutrition of higher plants. San Diego: Academic Press, 1995. 889p.

NACHTIGALL, G.R.; DECHEN, A.R. Seasonality of nutrients in leaves and fruits of apple trees. Scientia Agricola, Piracicaba, v. 63, n.5, p. 493-501, 2006.

NAKAMURA, N.; KAWASE, I.; GOTO, Y.; KANI, N.; HISAMATSU, S. A survey on the nutritional status of persimmon orchards in Gifu city area. 1. Selection of orchards for survey and results of first year determination. Research Bulletin of the Faculty Agriculture Gifu University, Kagamihara, n.33, p. 25-36, 1972a.
NAKAMURA, N.; KAWASE, I.; GOTO, Y.; KANI, N.; HISAMATSU, S. A survey on the nutritional status of persimmon orchards in Gifu city area. 2. The results of 2 nd and 3 rd year determination and conclusion based on thre years survey. Research Bulletin of the Faculty Agriculture Gifu University, Kagamihara, n.33, p.37-49, 1972 b.

ROBINSON, J.B. Fruits, vines and nuts. In: REUTER, D.J.; ROBINSON, J.B. Plant analysis, an interpretation manual. Melbourne: Inkata Press, 1986. p. 120-147.

SATO, K.; ISHIHARA, M.; HARADA, R. Studies on leaf analysis of fruit trees. 6. Leaf analysis in Japanese persimmon orchards. Bulletin of the National Institute of Agriculture Science Serie E, Yatabe, n.3, p. 169-186, 1954.

SHARPLESS, R. O.; JOHNSON, D.S. The influence of calcium on senescense changes in apple. Annals of the Applied Biology, Warewick, n.85, p. 450-453, 1977.

SMITH, F.W. Interpretation of plant analysis concepts and principles. In: REUTER, D.J.; ROBINSON, J.B. Plant analysis, an intrepretation manual. Melbourne: Inkata Press, 1986. p. 1-12.

SPARKS, D. Effects of fruiting on scorch, premature defoliation, and nutrient status of 'Chicksaw' pecan leaves. Journal of the American Society for Horticultural Science, Alexandria, n. 102, p. 669-673, 1977.

VITTI, G.C.; BOARETTO, A.E.; PENTEADO, S.R. Fertilizantes e fertirrigação. In: SIMPÓSIO BRASILEIRO SOBRE FERTILIZANTES FLUIDOS, 1. 1993. Piracicaba. Anais... Piracicaba: POTAFÓS, 1994. p. 261-280. 